\title{
FERNÁN GONZÁLEZ, S. J. (COMP.). (2020). CURAS GUERRILLEROS PATRIOTAS Y CURAS REALISTAS. BOGOTÁ: ACADEMIA COLOMBIANA DE HISTORIA, 628 P.
}

\author{
Roger Pita Pico ${ }^{\mathrm{I}}$
}

Innegable es para todos el gran influjo ejercido por la Iglesia en América desde los inicios del dominio hispánico a través de una presencia institucional que permeaba todos los ámbitos de la vida social, económica y cotidiana de entonces. Un poder que alcanzaba tanta preponderancia como el poder político, de manera que Dios y Rey se constituían en los máximos ejes de autoridad.

El siglo XIX despuntó con intensas convulsiones políticas tras irrumpir la etapa revolucionaria que comprometió tanto a España como a las colonias de ultramar, con lo cual se abrió paso en la Nueva Granada, en 1810, el periodo de Independencia, que se extendería por más de una década.

Desde luego, estos años de lucha política y conflicto militar no fueron ajenos al estamento eclesiástico. Integrantes del clero secular y regular intervinieron en este ambiente de agitación, algunos blandiendo el estandarte monárquico y otros expresando su adhesión a la causa emancipadora, sin que tampoco fueran extraños los cambios de postura y las lealtades vulnerables.

En especial, los curas mantuvieron una participación muy activa a escala regional por su cercanía e influencia en la población. En tiempos de guerra, resultó ampliado su campo de acción, desde el púlpito con apasionados sermones de tinte político hasta las juntas de gobierno como novedosos espacios de representación política. Algunos apoyaron de manera decidida a las tropas con auxilios y donativos e, incluso, llegaron a empuñar las armas. Así entonces, terminaron envueltos en la atmósfera de polarización y el juego de retaliaciones de uno y otro bando, ante lo cual padecieron el peso de las medidas represivas como encarcelamientos, destierros, saqueos, confiscaciones y fusilamientos.

1 Magíster en Estudios Políticos de la Pontificia Universidad Javeriana (Bogotá, Colombia, 2000). Politólogo de la Universidad de los Andes (Bogotá, Colombia, 1995). Director de la Biblioteca Eduardo Santos de la Academia Colombiana de Historia. Miembro de Número de la Academia Colombiana de Historia. Correo electrónico: rogpitc@ hotmail.com 
Los primeros relatos sobre el rol asumido por los curas los conocemos por cuenta de los protagonistas de la época: con las crónicas de José Manuel Restrepo y otros tantos testimonios, todo esto sumado a las fuentes primarias documentales como los juicios sumariales, los reportes de las autoridades militares y políticas, así como también los informes y el intenso cruce epistolar de la jerarquía eclesiástica.

En el marco de la Colección Bicentenario de la Independencia, la Academia Colombiana de Historia pone en circulación la obra Curas guerrilleros patriotas y curas realistas ${ }^{2}$. El papel de los curas en las gestas de Independencia ha llamado poderosamente la atención de varios académicos e investigadores, observándose, además, un gran interés por parte de algunos estudiosos integrantes de la Iglesia en su afán por develar las vicisitudes de sus antecesores en esa etapa crucial de la historia ${ }^{3}$. Amplio es también el repertorio de estudios para otras latitudes del mundo novohispano ${ }^{4}$.

La obra que hoy se presenta a la comunidad académica corresponde a una recopilación hecha por el padre jesuita Fernán González. Incluye un escrito introductorio y cuatro textos ya publicados por la Academia Colombiana de Historia en el siglo XX dentro del propósito de mostrar diversas facetas y posiciones ideológicas de los curas durante las guerras independentistas.

El primer texto, a modo de abrebocas reflexivo, estuvo a cargo del compilador en su intento por explicar cómo la jerarquía eclesiástica asumió el proceso de transición del antiguo régimen al naciente sistema republicano: los alcances de lo que él denomina "revolución clerical" y el impacto de las voces jerárquicas opositoras en la fase independentista temprana; las novenas y sermones como instrumentos de legitimidad y persuasión política en el marco de la confrontación de tendencias; el patronato eclesiástico y la relación con el Estado; las divisiones dentro del clero y las agitadas polémicas entre los curas patriotas y los curas realistas. González ahonda también en la trayectoria del cura Ignacio Mariño y en la difusión del catecismo de Juan Fernández de Sotomayor. Por otro lado, también aborda las diversas posturas asumidas por el Libertador Simón Bolívar frente a la Iglesia y las estrategias que aplicó en cada coyuntura. Esta revisión histórica no hace más que subrayar la complejidad misma vivida dentro de este estamento

2 Este título se suma a una zaga de obras producidas por esta entidad sobre Historia Eclesiástica: los estudios del Padre Luis Carlos Mantilla sobre los arzobispos de Santa Fe don Bartolomé Loboguerrero y don Hernando Arias de Ugarte, así como también las obras de los académicos Luis Martínez Delgado y Miguel Aguilera sobre la vida del arzobispo Manuel José Mosquera. Adicionalmente, hay que mencionar el libro de Luis García Benítez sobre la reseña histórica de la Diócesis de Santa Marta, la serie en cuatro tomos de José Restrepo Posada sobre la Arquidiócesis de Bogotá y, en especial, los cinco volúmenes de Historia Eclesiástica, a cargo del Padre jesuita Juan Manuel Pacheco, incluidos en la Historia Extensa de Colombia, punto clave de referencia y consulta.

3 Así, por ejemplo, cabe mencionar el libro de Alfonso Zawadzky Colmenares y de Roberto Jaramillo sobre el clero en la Independencia. Otros trabajos se han centrado, de manera especial, en la vida y trayectoria de algunos curas, respecto de lo cual vale citar las obras del emérito historiador Javier Ocampo López sobre Juan Fernández de Sotomayor y Andrés María Rosillo y Meruelos.

4 Para el proceso revolucionario en Espańa, puede consultarse el trabajo de Pedro Pascual sobre los curas y frailes guerrilleros (2000) y el de Manuel Moreno y Miguel Artola sobre el clero afrancesado (2014). Sobre la Independencia americana véanse los trabajos de Manuel Landaeta sobre los sacerdotes patriotas en Venezuela (1911), el de Javier Francisco Infante sobre los curas y frailes en Chile (2015), el de Roberto De Nancy y Klaus Gallo sobre los curas revolucionarios en Buenos Aires (2002), el de Pilar García-Jordán sobre el clero en el Perú (1982) y el de Roberto Blanco sobre los célebres curas mexicanos Miguel Hidalgo y José María Morelos (1978). 
con profundos matices provinciales y locales. A manera de colofón, González aborda las consecuencias de la participación de la Iglesia en los procesos de Independencia y su incidencia en las relaciones con los Estados latinoamericanos a lo largo de los siglos XIX y XX, ante los intentos de los liberales de avanzar hacia el camino de la modernización y la secularización. Finalmente, el autor llama a reflexionar sobre los retos de la Iglesia en un mundo actual "conflictivo y pluralista", además de las posibilidades que ofrece el adaptarse para responder a las nuevas realidades sociales.

Después de este marco reflexivo introductorio se incluye el primer texto reeditado, una semblanza que el padre franciscano Luis Carlos Mantilla escribió sobre el cura Francisco Antonio Florido, abordando sus diversas facetas ${ }^{5}$, ya fuera como orador o ideólogo de la causa emancipadora, así como su presencia en Ramiriquí en el ocaso de su vida.

Sigue, a continuación, una obra del padre Roberto María Tisnés, publicada por primera vez en 1963 y que aborda el papel desarrollado por fray Ignacio Marińo, de la Orden de Predicadores, como el más destacado y ferviente seguidor de la bandera independentista. El autor hace un recorrido por sus primeros años, sus estudios en Santa Fe y su función misionera en Tame en las primeras dos décadas del siglo XIX. También habla de su figuración en Tunja, en tiempos de Independencia, y, principalmente, su impronta como capellán del Ejército Libertador en los inicios de la Campaña Libertadora en los Llanos de Casanare. Su protagonismo continuó vigente gracias a su nombramiento como jefe civil y militar de Sogamoso. Varios títulos militares y reconocimientos de la jerarquía eclesiástica fueron un claro homenaje al aporte de este cura.

En cuarto lugar, se incorporan en esta recopilación histórica dos escritos de uno de los más caracterizados seguidores del régimen monárquico, el cura de Tabio, el criollo José Antonio de Torres y Peña. El primero de ellos publicado, por primera vez, en 1960 y compilado por el académico Guillermo Hernández de Alba, corresponde a las memorias sobre las primeras manifestaciones emancipatorias de la Nueva Granada y Venezuela, en donde se narran los antecedentes de los sucesos revolucionarios, haciendo énfasis en los factores sociales y económicos, en especial las rivalidades entre criollos y peninsulares. Culmina con los acontecimientos posteriores a la revolución de 1810 y la prisión del virrey y los oidores.

Cierra este libro la extensa obra en verso titulada Bogotá cautiva, publicada, por primera vez, en 1902, por Eduardo Posada. Allí, se describe la ocupación de Santa Fe, en 1814, por parte de las tropas de las Provincias Unidas de la Nueva Granada, al mando de Simón Bolívar y se lanzan fuertes críticas contra este militar por la represión que ejerció sobre la población. Es este un valioso documento no solo para la historiografía colombiana sino también para la literatura, por el esfuerzo de plasmar en versos aquellos sucesos cruciales, un experimento que se suma a otros anteriores, como el que redactó, a finales del siglo XVI, el sacerdote español Juan de Castellanos en su aclamada obra Elegías de Varones ilustres de Indias, sobre las gestas de conquista y colonización de América.

5 Sobre este cura véase además: Pita Pico, R. (2017). El cura Francisco Antonio Florido y su aporte al proceso de Independencia de Colombia: aproximaciones a las facetas de un patriota integral. 'Ilu. Revista de Ciencias de las Religiones, (22), 301-322. 
En resumidas cuentas, esta compilación constituye una valiosa fuente de consulta y de reflexión historiográfica sobre las implicaciones de la fase de Independencia y la activa participación de los curas en ella. Un claro recordatorio del papel preponderante de la Iglesia, de sus expectativas, de sus relaciones con el poder político y militar, y de sus complejas dinámicas internas en esa intrincada etapa del proceso de construcción nacional. 